Bol. Acad. peru. leng. 57. 2014 (213-223)

\title{
EN BUSCA DE ALOYSIUS ACKER
}

\author{
Rodrigo Núñez Carvallo
}

Fecha de recepción:

$23 / 04 / 2014$

Fecha de aceptación:

$26 / 04 / 2014$

Pocas obras "inexistentes" han suscitados tanto interés y controversia como el Aloysius Acker de Martín Adán. El largo poema fue desaparecido por su autor a finales de 1933, pero desde entonces no han dejado de aparecer fragmentos y versiones que se resistieron a morir. El proverbial desorden de Martín Adán y el celo de sus amigos, impidieron que se consumara la voluntad de su creador. Estas líneas buscan esclarecer las razones de tal destrucción, y desentrañar la identidad velada de Aloysius Acker.

Rafael de la Fuente tiene apenas quince años. En las aulas del Colegio Alemán comienza a escribir una novela, La casa de cartón. Cuando finalmente la termina, se hace acompañar por su condiscípulo Estuardo Núñez y se la entrega personalmente a José Carlos Martiátegui. A la semana siguiente el autor de los "Siete Ensayos", frente a un muchacho inseguro y nervioso, hojea los originales y con una sonrisa de satisfacción, exclama: “iEstupenda!”. El alma del muchacho bulle de satisfacción. Luego Mariátegui propone la publicación de un fragmento en la revista Amauta, y sigue comentándola desde su silla de ruedas. "Es ecléctica

https://doi.org/10.46744/bapl.201401.007 
y hereje, y hasta se diría que subvierte las reglas del género. Pero hay un ligero problema...", advierte. "Rafael de la Fuente Benavides es un nombre demasiado solemne para una obra tan heterodoxa. Necesitas un seudónimo, Rafael”.

Días después Mariátegui y Núñez, usando el método freudiano de las asociaciones libres vinculan el nombre que por lo general llevan los monos de los organilleros con el primer hombre. Martín Adán suena muy bien. "Como que reconcilia el Génesis con Darwin”, bromea Mariátegui. El autor de La casa de cartón acepta de buena gana la propuesta. No quiere que su tía Tarcila, cucufata y dominante, se entere de sus audacias literarias. En junio de 1928 aparece una edición de muy corto tiraje, sufragada en parte por el propio Adán. No son más de doscientos ejemplares que regala a sus amigos.

Martín Adán no se duerme sobre sus laureles. Tras la publicación de su primera novela lo invade un verdadero furor creativo. Lee caudalosamente y escribe sonetos un tanto futuristas que no alcanzan la calidad literaria de los poemas Underwood, incluidos en La casa de cartón. Pero a finales de 1928 surgen ya los primeros versos del Aloysius Acker, un largo y misterioso poema, cuyo destino será por demás azaroso.

\section{iAloysius Acker está naciendo \\ llenando de gritos la casa, el cielo! \\ iAloysius Acker está naciendo! \\ iAloysius Acker, hermano mío, \\ el hermano mayor, el hermano pequeño!}

iPara ti son plumas todas las almobadas,

$y$ con uno que no parece todos los sueños,

$y$ con aire todos los caminos

y con voces todos los versos!

El secreto persigue el poema desde sus primeras líneas. ¿Quién es el intrigante personaje cuya identidad el lector desconoce? ¿Un amigo, alguien conocido, un personaje inexistente? Durante años le pregunto a 
Estuardo Núñez pero invariablemente mi interlocutor voltea la mirada y se silencia.

\author{
Mi hermano hostil, mi hermano verdadero \\ según seno incapaz de la propia natura!... \\ iAy, echado, nonato, el ternísimo creo \\ a cenagosa estrella de inmediata ternura!...
}

Sigo acribillando a Estuardo Núñez: ¿Notaste algún signo en la personalidad de Adán que rechazabas? ¿Por qué dejaron de ser amigos o se alejaron? ¿Por la identidad hostil de la que habla el poeta? ¿Quién es el enigmático Aloysius Acker? El severo crítico calla en siete lenguas. ¿Se trata del respeto al amigo de la infancia que se envuelve en el mutismo, o la lealtad al compañero del colegio que se disfraza de ignorancia? O quizás Martín Adán es el que quiere huir. Tiene miedo de la mirada censora tras "los anteojos de Núñez".

¿Quemaré la casa paterna?... ¿partiré de la patria?

¿Seré un monje en un monasterio?...

¿Me echaré a marear, tatuado, barbudo, descalzo,

en el último de los veleros?

iTodo me es igual, Aloysius Acker!...

iSolo tú me eres idéntico!

\title{
EL AREÓPAGO
}

En los tiempos en que Martín Adán escribe el Aloysius se distancia de sus antiguos amigos, entre ellos Estuardo Núñez, su compañero de carpeta y de tranvía. Juntos han conocido a Eguren y a Mariátegui, se han prestado libros y han conversado arduamente en las tardes barranquinas, pero la vida termina separándolos. Martín Adán se ha mudado al centro de Lima. Vive ahora en la calle Corazón de Jesús, muy cerca de la Iglesia de los Huérfanos, y reúne en su casa a un consejo de jóvenes poetas en una tertulia a la que se bautiza pretenciosamente como el Aerópago, suerte de juzgado de los dioses. Visitan ese vetusto salón novísimas figuras: José 
Alfredo Hernández, José Alvarado Sánchez (que se hace llamar Vicente Azar), Enrique Peña Barrenechea, Luis Valle Goycochea y Luis Fabio Xammar, entre otros. Núñez no participa del Aerópago. Se ha enrolado en el movimiento de la reforma universitaria y ha optado por la crítica literaria. Prepara una tesis sobre Eguren.

La bolsa de Nueva York se hunde y la crisis mundial estalla. Para sobrevivir la familia de Martín Adán va devorándose sus pocas rentas. "Rafael será abogado felizmente", dice la tía Tarcila, que funge de jefa de un hogar ahogado por las hipotecas. Pero el poeta que ya terminó letras se aburre soberanamente en las clases de derecho. Prefiere tomarse alguna copa en algún huarique del centro, mientras sus compañeros participan en las asambleas de estudiantes o en la toma de la Casona de San Marcos. Desprecia la política y la acción. Se siente un poeta "puro", un francotirador antes que un militante. Es demasiado individualista para pertenecer a un movimiento o luchar por una causa colectiva.

Ya principia la vida, ya principia el mundo;

Ya principia el juego.

Jugamos a ser y no ser.

Yo no soy yo. Tú eres yo.

Jugamos a vivir y vivir.

Y tú mueres. Y yo muero.

En abril de 1931 arriba a Lima un personaje excepcional. El poeta Gilberto Owen es funcionario de la embajada mexicana y se rodea desde el principio de los jóvenes poetas que frecuentan el Areópago. José Alfredo Hernández, el olvidado poeta peruano autor de un poemario llamado Tren (1931), lo describe así: "Owen, como la palidez de su cutis, siempre fue un recuerdo; un recuerdo de algo que nos precedía”... También dirá que era "amigo de la noche y del suburbio, y supo exprimir a las madrugadas su encanto".

El mexicano que apenas es mayor que el resto de sus contertulios no es un advenedizo ni un diletante. Ha formado parte de un importante movimiento renovador de las letras aztecas llamado Los Contemporáneos, 
conjuntamente con Xavier Villaurrutia, Salvador Novo, Jaime Torres Bodet y Carlos Pellicer. No quieren hacer poesía comprometida y cultivan también la novela lírica. Pero sobre todo son audaces y desprejuiciados. Owen publica Novela como nube en 1928, el mismo año en que aparece $\mathrm{La}$ casa de cartón de Adán. Desde entonces encontraremos muchas simetrías entre ambos escritores.

$\mathrm{Al}$ poco tiempo de conocerse surge el proyecto de editar un libro en conjunto llamado Dos poemas de odio. Este incluiría El infierno perdido de Owen y el Aloysius Acker del peruano. El largo poema de Martín Adán está casi listo, aunque a decir verdad nunca terminan las correcciones. Es obsesivo y demasiado crítico con su obra. Nunca está conforme. El poemario de Owen también está muy avanzado. Curiosamente las dos obras se extravían o son destruidas antes de ver la luz.

De mí te apartas y eres como la imagen

en el espejo

¿Cuándo no eres yo mismo Aloysius Acker?

el esperado, el compañero,

el que me sorprende, el que no conozco

aquel por quien soy alguno y muero.

Los muchachos se reúnen continuamente en bares y en la casa de Owen. Son días de intensa vida bohemia que coinciden con nuevas lecturas y aventuras artísticas. Se discute la literatura, y siempre hay cantidades navegables de alcohol. También, se escuchan nocturnos y polonesas en la casa barranquina de Manuel Beltroy, que asoma sobre el mar. De tales audiciones nacen las primeras estrofas de Travesía de Extramares (Sonetos a Chopin).

Corre 1932. Mientras Martín Adán escribe con desenfreno en un país que se desbarranca, Gilberto Owen esconde a Haya de la Torre en una casa vecina a la embajada de México, situada en Miraflores. Cuando finalmente el líder opositor es capturado por la dictadura de Sánchez Cerro, el mexicano es inmediatamente expulsado. No tiene tiempo ni para hacer las maletas y en Guayaquil se entera de que también ha sido 
separado del cuerpo diplomático de su país. Desempleado pero siempre aventurero, Owen inicia una nueva vida en Bogotá. Sigue escribiendo poesía y trabaja muchos años en la redacción de El Tiempo. ¿Y El infierno perdido? Hace honor a su nombre y se traspapela en el camino. El proyecto de libro compartido que lo vincula a Martín Adán pasa al olvido. Nunca más se verían. Owen muere de cirrosis en 1952.

Alguna vez le pregunto a Estuardo Núñez si Gilberto Owen en Aloysius Acker. No, dice escuetamente. Luego añade: "El Aloysius ya estaba bastante avanzado cuando Owen llega al Perú. No sé si terminado, pero sí largamente trabajado, como lo evidencian las múltiples versiones que entregó a sus amigos o que perdió en medio de la noche”. ¿Quién es entonces el tal Aloysius Acker? Se abre un silencio. Conozco la mirada de Núñez cuando no quiere hablar. Me responde con una evasiva y sale apurado del comedor. Dentro de su moral luterana no tiene derecho a revelar intimidades ajenas.

\section{LA CASA COLUMBIA}

Por aquella época Martín Adán también frecuenta la casa musical Columbia de la calle Mantas. Allí la acuarelista y poeta ecuatoriana Isabel Ramos de Jaramillo, más conocida como Isajara, organiza todos los jueves exposiciones y veladas, teniendo siempre a José María Eguren como invitado especial. A esta tertulia llamada Los Duendes, — nombre de indudable resonancia egureniana-, asisten gentes de todas las edades: las hermanas de Izcue, Manuel Beingolea, Enrique Peña Barrenechea, Alberto Ureta, Arturo Jiménez Borja, Emilio Adolfo Westphalen y Estuardo Núñez, siendo una de las pocas ocasiones en que este último coincide con Martín Adán.

Martín Adán brilla en la tertulia de la casa Columbia. El joven que seguramente lleva en los bolsillos nuevos versos del Aloysius Acker enciende el diálogo con versación y agilidad. "No he conocido una persona más inteligente”, confiesa Núñez. Es irreverente y locuaz. Sus silogismos encandilan a los asistentes. Aún no ha calado en él la misantropía. Tiene apenas veintidós años y el abrigo un poco sucio. 
Vuelvo a la carga con Estuardo Núñez. ¿Era gay Martín Adán? le pregunto un día a mansalva. Sorprendentemente el estudioso que ya pasó los ochenta años, habla más de lo esperado: "Durante aquellas reuniones en la Casa Columbia, Martín Adán conoce a un sobrino de Isa Jara, casi de su misma edad". Con tono de censura, continúa: "El muchacho tiene una belleza totalmente andrógina y Martín Adán se deja arrastrar por la atracción. El acercamiento es más que platónico”. Núñez ha derribado por primera vez el muro de silencio. Sus ojos escrutadores brillan con cierto desdén, aunque luego lo disculpa: "Martín Adán vivía entre mujeres: la madre y la tía Tarcila. El abuelo, el padre, el hermano pequeño, se murieron cuando aun Martín Adán era niño. Carecía de figura masculina pues el único tío que tenía andaba encerrado en el techo, como todos los locos de Lima”.

Estuardo Núñez prosigue: "Se hacen amigos, pero el muchacho es un poco superficial y frívolo". ¿Era el Aloysius Acker del poema? "No, qué va, no puede serlo. El Aloysius Acker tiene una dimensión metafísica. Aquel muchacho era insustancial".

\author{
El que no eres tú es el otro, \\ el cavador del cementerio, \\ el taquígrafo, el mecanógrafo, \\ el que me espanta, el que no temo. \\ iVivir es estar tú cogido de mi mano! \\ iVivir es estar yo cogido de tu mano! \\ A veces te sueltas; \\ iy andas solo por la ciudad y el campo!
}

\title{
LA DESTRUCCIÓN
}

El Aloysius Acker es destrozado a finales de 1933, después de una estadía de Martín Adán en Arequipa como empleado del Banco Agrícola. Un testimonio de Augusto Tamayo lo recuerda al pie del Misti leyendo el Aloysius en tardes inverosímiles de picantería. Pero los excesos pasan la factura. Martín Adán sufre una aguda crisis depresiva, rompe en mil 
pedazos el inédito manuscrito, lleno de borrones y versiones alternativas e incompletas y se regresa a Lima. ¿Se avergüenza Martín Adán de un poema que lo transparenta tanto? ¿Lo detiene el pudor? Estuardo Núñez cree que sí. Más allá de que adujera que se trataba de un texto "hechizo y simbolista", y que incluso no lo reconociera como suyo, lo cierto es que se deshace de él con la intención de desaparecer su pasado. Se arrepiente de haber mostrado tan descarnadamente su pasión. Más tarde y a modo de justificación dirá en otro poema: "pobre de aquel que realiza sus deseos".

Martín Adán solo salva seguramente en la memoria, algunos versos que después "reutiliza" en obras posteriores. Pero para sorpresa suya los amigos que le son incondicionales conservan algunas versiones. A Vicente Azar lo cautivó tanto el poema que lo menciona en una nota periodística publicada en la revista Social a comienzos de 1934. Un poco después, en un artículo en El Comercio titulado Margen de Eternidad y fechado en 1936, Luis Fabio Xammar asegura que existen fragmentos de él en manos de algunos amigos que sobreviven al original roto por el autor.

Entre los papeles que el poeta Alberto Ureta donó a la Biblioteca Nacional se encontraron otros tantos parágrafos y otros poemas que integrarían tentativamente el Aloysius Acker. Y en 1947, Luis Valle Goycochea entregó a Emilio Adolfo Westphalen para su publicación en el primer número de la revista Las Moradas la versión más extensa conocida. Por su parte Fernando Tovar se ufanaba como buen bibliófilo de guardar celosamente una compilación bastante completa del poemario. Aseguraba que el poeta se lo había dado a guardar en una noche de copas, y fue esta versión la que utilizó Eielson para escribir un artículo sobre Martín Adán en los cuarentas. En 1971 Ricardo Silva Santisteban reunió todos los descubrimientos y les dio un orden secuencial, añadiendo algunas partes más. Lo cierto es que el poema o gran parte de él resucitó milagrosamente.

El que no eres tú, no es nadie.

El que no eres tú, es alguien,

Aloysius Acker. 


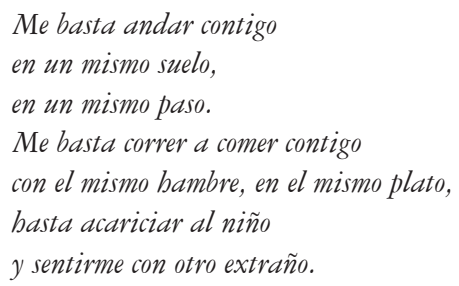

Releyendo el texto reconstruido podemos aseverar que el Aloysius no es una elegía a la muerte ni un lamento, sino una búsqueda dionisíaca con todos los riesgos que ello implica. El poeta va en pos de su doble, de su yo oculto, enmascarado, y descubre la posibilidad de establecer un amor con un personaje imaginario. A Martín Adán le hubiera gustado ser y poseer a Aloysius, pero esa completud no puede realizarse. Son tiempos difíciles. El poeta carece de voluntad para todo, salvo para escribir, y las convenciones sociales parecen infranqueables. Más tarde creerá que este largo poema es solo un delirio de juventud y por eso lo destruye. Aloysius Acker ha muerto.

\author{
iMuerto!... \\ En cuanto miro, no veo \\ Sino tu nariz de bielo. \\ iQué estado perfecto!... \\ iComo si Dios creara de cierto!... \\ iEl no nacido, el no engendrado, muerto!... \\ Flores, lágrimas, candelas, \\ Pensamientos,
}

Tras los funerales del Aloysius Acker, a Martín Adán solo le queda la incompletud, y el alcohol. Tienes sucesivas entradas y salidas del Larco Herrera, donde el psiquiatra Honorio Delgado, todavía freudiano, le cede un cuarto al lado de la dirección, y le concede un régimen bastante abierto. No puede castrar el alma de artista porque solo la poesía lo puede redimir. Sin embargo la psicoterapia no da resultados. Martín Adán a veces huye en busca de la noche y ataja el verso escribiendo en cajetillas de cigarrillos y en servilletas ajadas. El alcohol le produce una extraña 
exaltación, y una tormentosa lucidez. Las palabras acuden en tropel y los juegos conceptuales invaden su poesía y su conversación. En su cabeza estallan en premeditado desorden ideas, imágenes sonoras, las palabras precisas para edificar una metafísica de la desesperanza. El alcohol y la poesía le ocultan transitoriamente el ghetto, el exilio, y el ocultamiento, al que la sociedad lo condena por tener una condición sexual distinta.

Martín Adán finalmente no puede encarnarse en Aloysius, que aparece como una tierra prometida. No por casualidad Acker en alemán es campo de labranza, antónimo de lo yermo y lo estéril. Cuando arroja al cesto su largo poema, opta por la destrucción y la auto marginación. Bebe mucho, anda en malas juntas, acepta cualquier amigo ocasional de cantina. Transita de madrugada en madrugada por los sitios más borrascosos de Lima, mordiendo la derrota a cada paso. No me extrañaría que aquel célebre fragmento de Escrito a ciegas perteneciera originalmente al Aloysius, pero tiene el mismo tono y el mismo ritmo:

Yo buscaba otro ser

Y ese ha sido mi buscarme;

Yo no quería ni quiero ya ser yo,

Sino otro que se salvara o que se salve"

\section{EL DESCUBRIMIENTO}

¿Pero quién es finalmente Aloysius Acker? Una noche de sábado dos de los nietos de Estuardo Núñez, que por entonces atisba los cien años le tienden una celada. Quieren resolver de una vez por todas el enigma del Aloysius. Sandro y Fernando sienten que es la última oportunidad de conocer la identidad del misterioso protagonista del poema, antes de que el polvo del olvido lo desvanezca todo.

Se ubican en la mesa del comedor alrededor de una botella de pisco. Al lado están el ginger ale, el jarabe de angostura, limones, una hielera y algunos entremeses. Los chilcanos ya están listos para ser servidos. Algunos libros de Martín Adán reposan en una mesa lateral, listos para iniciar el recital. Van y vienen los vasos cuando Estuardo pasa con rumbo 
a la cocina y pregunta qué están tomando. "Unos chilcanos y leyendo a Martín Adán”, responden y lo invitan a sentarse a la mesa. El abuelo accede, los chilcanos siempre son una tentación, quizás desde aquella vez en que Martín Adán y Núñez fueron a visitar a Jorge Guillermo Leguía, director del museo de historia de la Magdalena y tras unos piscos se probaron el uniforme de gala de don Simón Bolívar. Solo a Martín Adán le entraba. Entonces era flaco y esmirriado, luego engordó, usaba unos anteojos redondos de carey y le salió papada. ¿Qué año sería? ¿1928? Sí, apenas publicada $L a$ casa de cartón.

Estuardo Núñez ya va en el segundo chilcano. La circulación cerebral se aviva y los nietos lo llevan por los vericuetos del pasado. ¿Cuéntanos, abuelo, existió realmente Aloysius Acker? Las barreras se desvanecen y las ganas de seguir hablando se exacerban. "Sí, claro, yo lo conocí", dice con los ojos muy abiertos. "Era rubio y muy bien trajeado. Vivía en Barranco por la bajada de los baños. Era un muchacho de unos veinticinco años muy apuesto y elegante, hijo de un agente comercial alemán apellidado Döering, que salía a pasear al atardecer. Martín Adán buscaba cualquier pretexto para ir a observarlo cerca al Puente de los Suspiros. Cuando descubrí su verdadero objetivo dejé de acompañarlo. No sé si alguna vez conversaron o trabaron amistad. Lo único cierto es que en él se inspiró Martín Adán para componer el Aloysius".

Yazgo, muerto.

Ypor ti no llora el perro;

Y por ti no aúlla la madre;

Y por ti calla y no se enjuga el sepulturero. 